\title{
Lung sound intensity in patients with emphysema and in normal subjects at standardised airflows
}

\author{
H J W Schreur, P J Sterk, J Vanderschoot, H C J van Klink, E van Vollenhoven, \\ J H Dijkman
}

\begin{abstract}
Background A common auscultatory finding in pulmonary emphysema is a reduction of lung sounds. This might be due to a reduction in the generation of sounds due to the accompanying airflow limitation or to poor transmission of sounds due to destruction of parenchyma. Lung sound intensity was investigated in normal and emphysematous subjects in relation to airflow.
\end{abstract}

Methods Eight normal men (45-63 years, $F E V_{1} 79-126 \%$ predicted) and nine men with severe emphysema (50-70 years, FEV, 14-63\% predicted) participated in the study. Emphysema was diagnosed according to pulmonary history, results of lung function tests, and radiographic criteria. All subjects underwent phonopneumography during standardised breathing manoeuvres between 0.5 and 21 below total lung capacity with inspiratory and expiratory target airflows of 2 and $11 / \mathrm{s}$ respectively during 50 seconds. The synchronous measurements included airflow at the mouth and lung volume changes, and lung sounds at four locations on the right chest wall. For each microphone airfiow dependent power spectra were computed by using fast Fourier transformation. Lung sound intensity was expressed as $\log$ power (in dB) at $200 \mathrm{~Hz}$ at inspiratory flow rates of 1 and $21 /$ s and at an expiratory flow rate of $11 / s$.

Results Lung sound intensity was well repeatable on two separate days, the intraclass correlation coefficient ranging from 0.77 to 0.94 between the four microphones. The intensity was strongly influenced by microphone location and airflow. There was, however, no significant difference in lung sound intensity at any flow rate between the normal and the emphysema group.

Conclusion Airflow standardised lung sound intensity does not differ between normal and emphysematous subjects. This suggests that the auscultatory finding of diminished breath sounds during the regular physical examination in patients with emphysema is due predominantly to airflow limitation.

(Thorax 1992;47:674-679)
Pulmonary emphysema is associated with morphological lesions within the acini of the lung. ${ }^{1}$ It is defined as a condition characterised by abnormal permanent enlargement of the airspaces distal to the terminal bronchioles, accompanied by destruction of their walls, without obvious fibrosis. ${ }^{2}$ The diagnosis of emphysema during life is based on clinical history, physical examination, chest radiography, and lung function testing. ${ }^{12}$ A traditional characteristic feature of emphysema is the auscultatory finding of diminished intensity of lung sounds. ${ }^{2-4}$ This can be caused either by poor transmission of sounds as a result of parenchymal destruction or by reduced generation of sounds due to airflow limitation. ${ }^{5-7}$

Phonopneumography has shown that even normal subjects have considerable intersubject and intrasubject variability in the intensity of the inspiratory vesicular sounds heard on the chest wall. ${ }^{89}$ In patients with emphysema this variability seems to be much greater. ${ }^{710}$ Ploysongsang et al found that lung sound transmission is often abnormal in patients with emphysema, being reduced in some areas of the lung but normal or even increased in other areas. ${ }^{7}$ In addition, they observed that regional breath sounds vary from breath ts breath. $^{7}$ When measured at various locations on the chest, regional sound intensity appeared to be related to regional ventilation, ${ }^{10}$ which points to a potential role of airflow limitation in the reduction of lung sounds in emphysema.

In healthy human volunteers lung sound intensity is highly dependent on airflow at the mouth. ${ }^{11}$ The frequency spectrum of lung sounds, however, does not seem to be affected by airflow. ${ }^{12}$ These findings were extended by other studies, indicating that lung sound intensity increased with the square of both inspiratory and expiratory flow. ${ }^{1314}$ Airflow limitation therefore might be one of the major determinants of diminished breath sounds in patients with emphysema.

The objective of the present study was to test the hypothesis that lung sound intensity is similar in normal subjects and in patients with emphysema when measured at equal airflow rates. We therefore measured lung sound intensity by airflow standardised phonopneumography in normal and emphysematous men. As the within subject variability of lung sound intensity has been reported to be relatively high, ${ }^{89}$ we also determined the 
Table 1 Characteristics of the subjects

\begin{tabular}{|c|c|c|c|c|c|c|}
\hline $\begin{array}{l}\text { Subject } \\
\text { No }\end{array}$ & Age (y) & History & $\begin{array}{l}F E V_{1} \text {-pre } \\
\text { (\% pred) }\end{array}$ & $\begin{array}{l}\text { TLCo } \\
\text { (\% pred) }\end{array}$ & Smoking & Treatment \\
\hline 1 & 62 & $\mathbf{N}$ & $126 \cdot 0$ & $108 \cdot 6$ & + & - \\
\hline 2 & 55 & $\mathbf{N}$ & $125 \cdot 3$ & $137 \cdot 3$ & - & - \\
\hline 3 & 62 & $\mathbf{N}$ & $121 \cdot 8$ & 113.4 & - & - \\
\hline 4 & 60 & $\mathbf{N}$ & $104 \cdot 3$ & $85 \cdot 5$ & Ex & - \\
\hline 5 & 61 & $\mathbf{N}$ & $88 \cdot 7$ & $93 \cdot 6$ & + & - \\
\hline 6 & 45 & $\mathbf{N}$ & $87 \cdot 5$ & $89 \cdot 8$ & - & - \\
\hline 7 & 63 & $\mathbf{N}$ & $86 \cdot 6$ & $94 \cdot 5$ & + & - \\
\hline 8 & 62 & $\mathbf{N}$ & $79 \cdot 2$ & $77 \cdot 6$ & + & - \\
\hline 9 & 70 & $\mathbf{E}$ & $63 \cdot 1$ & $55 \cdot 3$ & Ex & OX \\
\hline 10 & 53 & $\mathrm{E} \alpha_{1}$ & $40 \cdot 8$ & $67 \cdot 6$ & Ex & I $\beta_{2}$, IC, Crom \\
\hline 11 & 70 & $\mathbf{E}$ & $40 \cdot 7$ & $40 \cdot 0$ & Ex & IA, I $\beta_{2}, \mathrm{OC}, \mathrm{OX}$ \\
\hline 12 & 70 & $\mathbf{E}$ & $35 \cdot 5$ & - & Ex & IA, I $\boldsymbol{\beta}_{2}, \mathbf{I C}$ \\
\hline 13 & 68 & $\mathbf{E}$ & $31 \cdot 4$ & $66 \cdot 5$ & Ex & $\mathrm{I} \boldsymbol{\beta}_{2}, \mathrm{IC}, \mathrm{OC}, \mathrm{OX}$ \\
\hline 14 & 57 & $\mathbf{E}$ & $25 \cdot 4$ & $67 \cdot 2$ & Ex & $\mathrm{I} \beta_{2}, \mathrm{O} \beta_{2}, \mathrm{IC}$ \\
\hline 15 & 50 & $\mathbf{E} \alpha_{1}$ & $23 \cdot 1$ & $37 \cdot 4$ & - & $\mathrm{I} \beta_{2}, \mathrm{OC}, \mathrm{OX}$ \\
\hline 16 & 68 & $\mathbf{E}$ & $21 \cdot 3$ & $37 \cdot 4$ & Ex & $\mathrm{I} \beta_{2}, \mathrm{IC}, \mathrm{OX}$ \\
\hline 17 & 69 & $\mathbf{E} \alpha_{1}$ & $14 \cdot 3$ & $20 \cdot 9$ & 一 & IA \\
\hline
\end{tabular}

FEV -pre-forced expiratory volume in one second, measured before bronchodilatation; TLCo-transfer factor for carbon monoxide; $\mathrm{N}$-normal; E-emphysema; $\alpha_{1}-\alpha_{1}$ antitrypsin deficiency; - - non-smoker; + -smoker; ex-ex-smoker; IA-inhaled anticholinergic; I $\beta_{2}$-inhaled $\beta_{2}$ adrenergic; $O \beta_{2}$-oral $\beta_{2}$ adrenergic; IC—inhaled steroid; OC-oral steroid; OX-oral xanthine derivative; Crom-sodium cromoglycate.

repeatability of the airflow standardised measurements.

\section{Methods}

DESIGN OF THE STUDY

The study consisted of two parts.

Part 1 For the comparison of lung sound intensity in normal and in emphysematous subjects we had a screening day (for checking the inclusion criteria) and a study day for both groups. On the study day phonopneumography was carried out while subjects were breathing at standardised flow rates.

Part 2 The repeatability of the measurements was investigated in normal subjects, who visited the laboratory on two separate days one to three days apart. On each day they underwent airflow standardised phonopneumography.

\section{SUBJECTS AND INVESTIGATIONS}

Part 1 Eight normal subjects (45-63 years) and nine patients with severe emphysema (5070 years) participated in this study. The normal subjects were recruited from hospital personnel and acquaintances and the patients were selected from outpatients of the department of pulmonology. The normal subjects had no history of lung disease, no abnormalities found by physical examination, a normal chest radiograph, ${ }^{15}$ and normal forced expiratory volume in one second $\left(\mathrm{FEV}_{1}: 79-126 \%\right.$ predicted $)^{16}$ (table 1). The patients with emphysema had had clinical symptoms of emphysema, such as regular wheezing and prominent dyspnoea after exercise, for several years. Physical examination showed tachypnoea, prolonged expiration, a hyperresonant chest, and diminished breath sounds on regular auscultation. The diagnosis of emphysema was based both on the appearance of the chest radiograph (paucity of peripheral arteries and abnormal length and width of the lungs and size of the retrosternal space, heart size, and diaphragm position $)^{15}$ and on the results of lung function tests. ${ }^{16}$ All patients had a decreased $\mathrm{FEV}_{1}(14$ $63 \%$ predicted $)^{16}$ and the measurements of $\mathrm{FEV}_{1}$ after inhalation of $200 \mu \mathrm{g}$ salbutamol showed that little of the decrease was reversible-less than $10 \%$ of the predicted value (table 1). In addition, transfer factor for carbon monoxide (TLCO), measured by the single breath holding technique, was reduced in all patients $\left(21-68 \%\right.$ predicted). ${ }^{16}$ The clinical condition of the patients was stable, and none had had symptoms of respiratory tract infections during the two weeks before the tests. At the time of the study treatment was continued as usual (table 1). The study was approved by the hospital ethics committee, and all subjects gave informed consent.

Part 2 The repeatability of the measurements of lung sound intensity was examined in 10 normal male volunteers (23-42 years, FEV $91-124 \%$ predicted) ${ }^{16}$ with no history of pulmonary disease. The subjects were recruited from hospital personnel. All were nonsmokers, and at the time of the study none of them used any medication.

\section{PHONOPNEUMOGRAPHY}

The experiments included synchronous recordings of airflow and lung volume changes at the mouth, obtained by spirometry (Morgan Spiroflow, UK), and phonopneumography in a sound proof room. Lung sounds were recorded with four identical air coupled piezoelectric microphones (Sony ECM-150T) at standardised locations on the right chest. Microphone 1 ( $\left.\mathrm{Mic}_{1}\right)$ and microphone $2\left(\mathrm{Mic}_{2}\right)$ were attached over respectively the 2 nd and the 5 th intercostal space at the midclavicular line, microphone $3\left(\mathrm{Mic}_{3}\right)$ over the 4 th intercostal space at the midaxillar line, and microphone 4 $\left(\mathrm{Mic}_{4}\right)$ over the 9th intercostal space at the midscapular line. The air coupled microphones (sensitivity $2.5 \mathrm{mv} / \mathrm{Pa}$ signal to noise ratio $\geqslant 40 \mathrm{~dB}(0.1 \mathrm{~Pa}, 1 \mathrm{kHz})$, band width $300 \mathrm{~Hz}$ $-20 \mathrm{kHz} \pm 3 \mathrm{~dB}$ ) were mounted in stainless steel housings that were fixed to the chest wall 


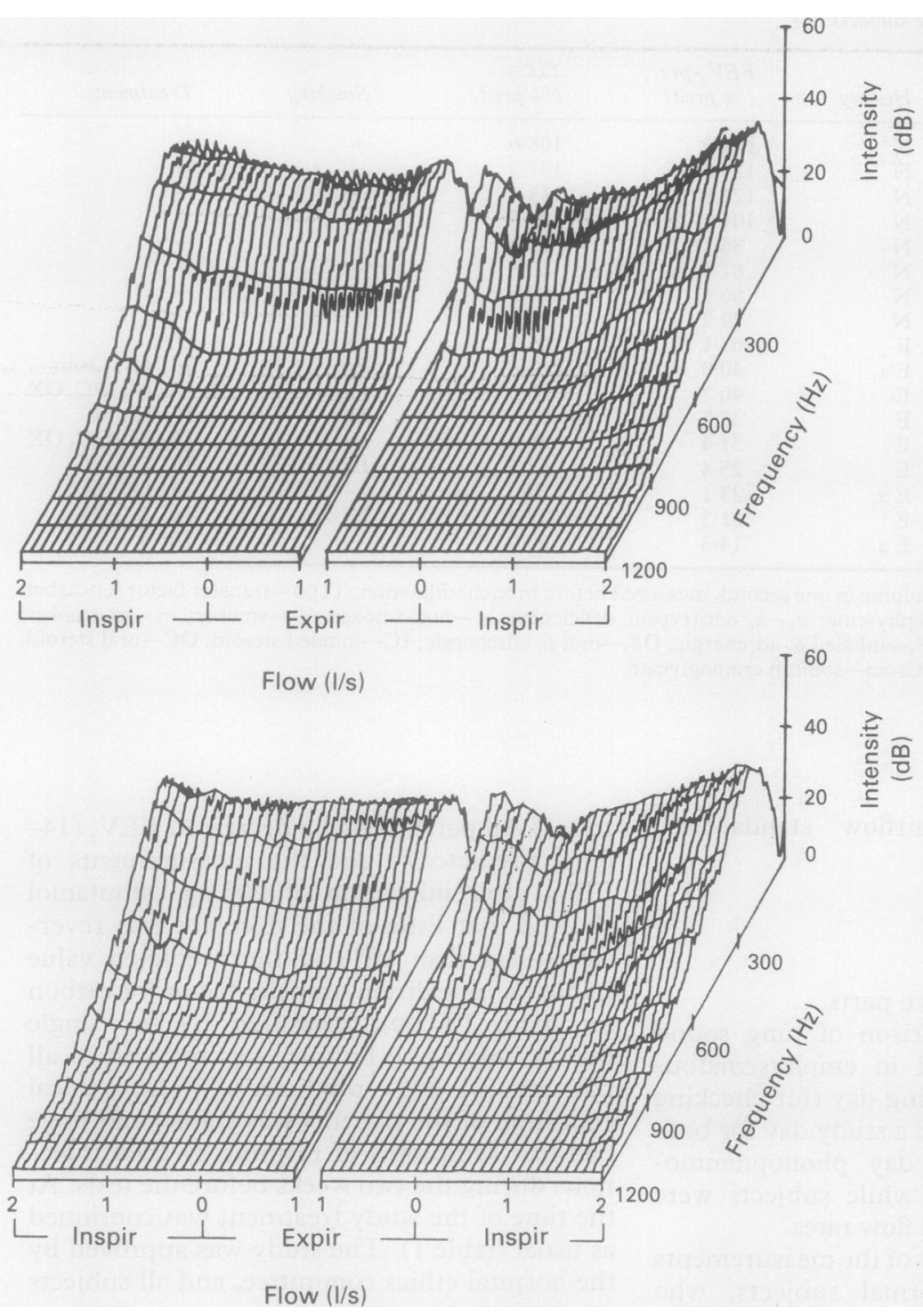

Figure 1 Typical examples of three dimensional diagrams of airflow standardised power spectra in a normal subject (top) and a patient with emphysema (bottom), showing the relation between airflow ( $x$ axis), sound frequency ( $y$ axis), and lung sound intensity ( $z$ axis). These figures are the results of averaging the spectra of 14 respiratory cycles. The left and right parts of the figure represent respectively the rising and descending segments of the flow curve. ing manoeuvres between TLC-0.5 1 and TLC21 with inspiratory and expiratory target flows of 2 and $11 / \mathrm{s}$ respectively in cycles of 3 seconds during 50 seconds.

\section{ANALYSIS}

For each microphone airflow dependent power spectra were computed by means of the fast Fourier transform method. The power spectra were analysed on $100 \mathrm{~ms}$ lung sound intervals, a Hanning window being used. These intervals were centred around lung sound samples that were corresponding in time to airflow samples at which the airflow was a multiple integer of $0.1 \mathrm{l} / \mathrm{s}$. The spectra obtained in this way were averaged between all complete breathing cycles of one registration for each distinct airflow value, and for the ascending and the descending limb separately. This resulted in three dimensional diagrams of an averaged breathing cycle, showing the relation between airflow (in $1 / \mathrm{s}, x$ axis), lung sound frequency (in $\mathrm{Hz}, y$ axis), and the logarithm of the lung sound intensity (in $\mathrm{dB}, z$ axis), and separately for the rising and the descending limb of the flow curve (fig 1). Fast Fourier transform spectra were determined for every $0.1 \mathrm{l} / \mathrm{s}$. To express lung sound intensity within and between the groups of subjects, the $\log$ power at $200 \mathrm{~Hz}$ was measured at inspiratory airflows of $2 \mathrm{l} / \mathrm{s}\left(\mathrm{LSI}_{2 \text { in }}\right)$ and $1 \mathrm{l} / \mathrm{s}\left(\mathrm{LSI}_{1 \text { in }}\right)$ and at an expiratory airflow of $1 \mathrm{l} / \mathrm{s}\left(\mathrm{LSI}_{1 \mathrm{lex}}\right)$. At $0 \mathrm{l} / \mathrm{s}$ the slope of the airflow versus time curve is rather steep. Thus the interval of $100 \mathrm{~ms}$ centred on this airflow will comprise lung sounds generated at airflow values from about $0.35 \mathrm{l} / \mathrm{s}$ on inspiration to $0.55 \mathrm{l} / \mathrm{s}$ on expiration. Unfortunately, this is inevitable when fast Fourier transforms are used if frequency resolution is not to be lost. For this reason $0 \mathrm{l} / \mathrm{s}$ has not been used for the statistical comparison.

The frequency of $200 \mathrm{~Hz}$ was chosen as the maximal energy of lung sounds has been reported to occur from 116 to $350 \mathrm{~Hz},{ }^{13}{ }^{17-19}$ whereas muscle and heart sounds have frequencies predominantly below $100 \mathrm{~Hz} .{ }^{17}$ We decided to measure the intensity at one frequency, as the power spectra in the three dimensional plots from all subjects, both normal and emphysematous, were very similar in shape, and very smooth. Furthermore, during inspection of the three dimensional diagrams and time expanded wave forms there was no evidence for crackles ${ }^{20}$ or wheezes ${ }^{21}$ that could influence the intensity of the lung sounds.

The repeatability of the results of lung sound intensity measurements was computed by using $95 \%$ confidence intervals of the differences between day 1 and day $2,{ }^{22}$ and by using the intraclass correlation coefficient obtained by analysis of variance for repeated measurements. ${ }^{23}$ The intraclass correlation reflects the ratio of the between subject variability to the between subject plus within subject variability of the measurements. The differences in lung sound intensity between normal subjects and patients with emphysema were analysed by multivariate analysis of variance, with airflow, microphone and group as independent variables. We considered $p$ values less than 0.05 of the subjects on an oscilloscope screen (Hewlett-Packard HP 1741A). First the subjects were asked to inhale towards total lung capacity (TLC), which was used as a reference volume. Subsequently they performed breath- 
Figure 2 Mean lung sound intensity with standard errors in eight normal and nine emphysematous subjects for each of the microphone locations (Mic, ) and three levels of airflow $(1 \mathrm{l} / \mathrm{s}$ expiratory, $1 \mathrm{l} / \mathrm{s}$ inspiratory, and $2 \mathrm{l} / \mathrm{s}$ inspiratory).
Figure 3 Identity plot of lung sound intensity (LSI) measurements between day 1 and day 2 for four microphone locations and three levels of airflow.

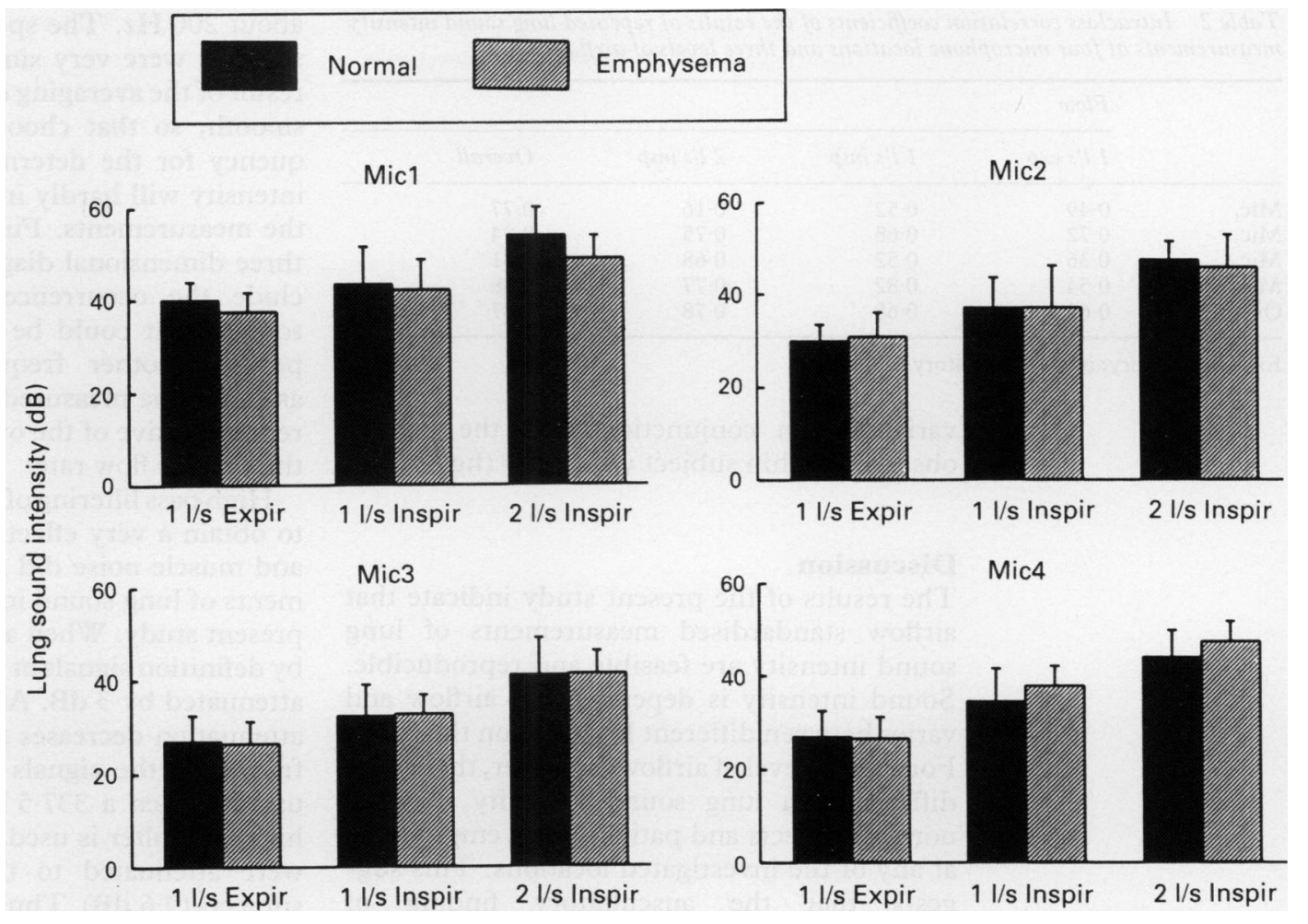

statistically significant. The statistical power of this analysis was calculated on the basis of our data on repeatability. The number of subjects in each group was sufficiently large to detect a difference in lung sound intensity of $4.77 \mathrm{~dB}$ within groups and $7 \cdot 16 \mathrm{~dB}$ between groups $(n=9)$, with a statistical power ${ }^{24}$ of 0.9 .

\section{Results}

PART 1

Satisfactory recordings could be obtained in all subjects. Representative examples of three dimensional diagrams in one normal (top) and one emphysematous subject (bottom) are shown in figure 1 . The frequency spectra of the lung sounds appeared to be similar in normal and emphysematous subjects and ranged from

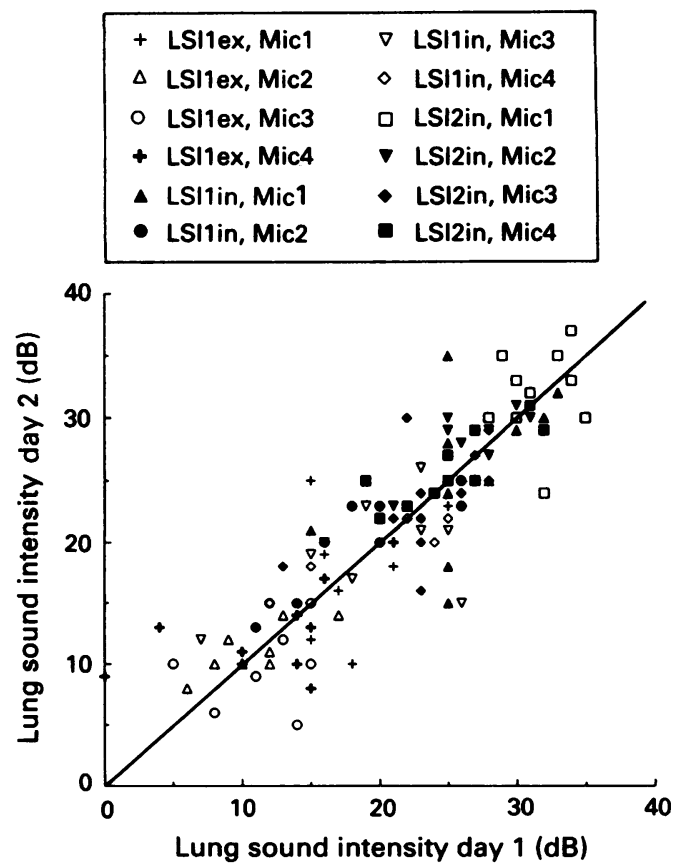

40 to $1100 \mathrm{~Hz}$, the highest frequencies occurring during inspiration at $2 \mathrm{l} / \mathrm{s}$.

There was a considerable variability in the measured lung sound intensity both within and between subjects. Lung sound intensity was significantly influenced by microphone location $(p<0.005)$ and by airflow $(p<0.005)$. In both groups of subjects lung sounds from the microphone placed midclavicularly over the second intercostal space $\left(\mathrm{Mic}_{1}\right)$ were the loudest, whereas lung sounds from the microphone placed under the armpit $\left(\mathrm{Mic}_{3}\right)$ were the weakest (fig 2). Lung sound intensity was greatest at $21 / \mathrm{s}$ inspiratory flow, less at $11 / \mathrm{s}$ inspiratory flow, and least at $1 \mathrm{l} / \mathrm{s}$ expiratory flow (fig 2). When these effects of microphone location and airflow were taken into account, however, there was no significant difference in lung sound intensity between the normal and the emphysema group ( $p=0.72$; fig 2 ).

PART 2

When the repeatability of the recordings was analysed there was no significant difference in lung sound intensity between the phonopneumographic registrations on the two days $(p=0.61)$. The identity plot of the results of lung sound intensity measurements between day 1 and day 2 is shown in figure 3 . The mean of the differences (with $95 \%$ confidence interval, CI) between repeated measures of intensity was found to be $-0.34(95 \% \mathrm{CI} 5.37) \mathrm{dB}$. The intraclass correlation coefficient varied between microphone locations and airflow levels (table 2). It ranged from 0.49 for $\mathrm{Mic}_{1}$ at $1 \mathrm{l} / \mathrm{s}$ expiratory flow to 0.82 for $\mathrm{Mic}_{4} 1 \mathrm{l} / \mathrm{s}$ inspiratory flow, with two outliers- 0.16 for $\mathrm{Mic}_{1}$ at $2 \mathrm{l} / \mathrm{s}$ inspiratory flow and 0.36 for $\mathrm{Mic}_{3}$ at $1 \mathrm{l} / \mathrm{s}$ expiratory flow. The relatively low intraclass correlations for these measurements appear to be due to a very limited between subject 
Table 2 Intraclass correlation coefficients of the results of repeated lung sound intensity measurements at four microphone locations and three levels of airflow

\begin{tabular}{lllll}
\hline & Flow & & \\
\cline { 2 - 5 } & 1 l/s exp & 1 l/s insp & $2 l /$ s insp & Overall \\
\hline Mic $_{1}$ & 0.49 & 0.52 & 0.16 & 0.77 \\
Mic $_{2}$ & 0.72 & 0.68 & 0.75 & 0.94 \\
Mic $_{3}$ & 0.36 & 0.52 & 0.68 & 0.81 \\
Mic $_{4}$ & 0.54 & 0.82 & 0.77 & 0.88 \\
Overall & 0.69 & 0.68 & 0.78 & 0.87 \\
\hline
\end{tabular}

Exp-expiratory; insp-inspiratory.

variability in conjunction with the usually observed within subject variability (fig 3 ).

\section{Discussion}

The results of the present study indicate that airflow standardised measurements of lung sound intensity are feasible and reproducible. Sound intensity is dependent on airflow and varies between different locations on the chest. For a given level of airflow, however, there is no difference in lung sound intensity between normal subjects and patients with emphysema at any of the investigated locations. This suggests that the auscultatory finding of diminished lung sounds in emphysema is predominantly due to concurrent airflow limitation.

The reduction of the intensity of lung sounds in patients with emphysema has been extensively reported..$^{2-4}$ In these publications, however, breathing manoeuvres were not standardised, nor was sound intensity measured at specific levels of airflow. With the traditional approach there appeared to be an inverse relation between lung sound intensity and the degree of airflow limitation in patients with airways obstruction. ${ }^{3525}$ Thus it is not entirely unexpected that sound intensity in patients with emphysema is similar to that in normal subjects when recorded at the same level of airflow.

The present results might be affected by methodological errors-for example, in selection of subjects, methods of measurements, or analysis. Firstly, the diagnosis of emphysema was based on pulmonary history and findings from the physical examination, ${ }^{2}$ lung function values ${ }^{16}$ and the chest radiograph. ${ }^{15}$ It could be argued that emphysema is a morphological diagnosis that cannot be made without pathological evidence from tissue samples. The specificity of the chest radiograph for the pathological lesions is, however, sufficiently large to justify its use in confirming the presence of moderate to severe emphysema. ${ }^{1526}$ The present selection criteria do not allow us to specify the subtype of emphysema any further.

Secondly, the microphones, their localisation, and signal processing were standardised as much as possible. Each microphone was consistently used at the same standardised location. Lung sound intensity was determined at $200 \mathrm{~Hz}$, which represents the centre of the range of frequencies observed by others to contain the maximum energy of lung sounds. ${ }^{13}{ }^{17-19}$ In addition, despite high pass filtering at $337.5 \mathrm{~Hz}$ the maximum energy in our three dimensional diagrams coincides with about $200 \mathrm{~Hz}$. The spectra obtained from the subjects were very similar in shape and (as a result of the averaging of the spectra) were very smooth, so that choosing only a single frequency for the determination of lung sound intensity will hardly influence the accuracy of the measurements. Further, inspection of the three dimensional diagrams enabled us to exclude the occurrence of adventitious lung sounds that could be responsible for energy peaks at other frequencies. We therefore assumed the measured power at $200 \mathrm{~Hz}$ to be representative of the overall sound intensity at the specific flow rate.

High pass filtering of lung sounds at $337.5 \mathrm{~Hz}$ to obtain a very effective elimination of heart and muscle noise did not invalidate measurements of lung sound intensity at $200 \mathrm{~Hz}$ in the present study. When a high pass filter is used, by definition signals at the cut off frequency are attenuated by $3 \mathrm{~dB}$. Above this frequency the attenuation decreases to $0 \mathrm{~dB}$, and below this frequency the signals are increasingly attenuated. When a $337.5 \mathrm{~Hz}$ fourth order Bessel high pass filter is used, lung sounds at $200 \mathrm{~Hz}$ were attenuated to the same extent in all subjects $(9.6 \mathrm{~dB})$. Thus the ratio of lung sound intensity observed in normal subjects to that in patients with emphysema has not been affected. As we measured intensity as log power, the differences of lung sound intensity (in $\mathrm{dB}$ ) between subjects will not have changed either.

Thirdly, the present data on the repeatability of lung sound intensity measurements confirm the validity of our methods. The intraclass correlation showed that the between subject variability in lung sound intensity is sufficiently large in relation to the total variability (between and within subjects), ${ }^{23}$ even within this relatively homogeneous group of normal subjects. Further, the power analysis showed that a difference in lung sound intensity of at least $7 \cdot 16 \mathrm{~dB}$ could have been detected between the normal and the emphysematous subjects in the present study. This difference is sufficiently small in relation to the effects of the other determinants of lung sound intensity, such as location on the chest wall and airflow (fig 2). The absence of diminished lung sounds in emphysema in the present study is therefore unlikely to have been caused by methodological errors.

How can we explain the similarity of lung sound intensity in normal and emphysematous subjects? Normal "vesicular" breath sounds are considered to originate predominantly from complex turbulence within the central airways. ${ }^{27}{ }^{28}$ Minor contributions to normal breath sounds may be generated by unsteady movement of vortices formed at junctions in the fifth to the 13th generations in the human bronchial tree. ${ }^{1429}$ It has, however, been suggested that inspiratory vesicular lung sounds are partly generated by other still unexplained mechanisms. ${ }^{814} 28$ We do not know whether any of these mechanisms is influenced by the mechanical changes within the lung during the development of pulmonary emphysema. The disease is characterised by parenchymal destruction leading to alveolar enlargement and loss of alveolar attachments to the bron- 
chioles. ${ }^{130}$ This is reflected physiologically by a decrease in lung elastic recoil pressure, an increase in lung volume, and airflow limitation. $^{12}$ Theoretically, the parenchymal destruction may change the transmission of lung sounds, whereas the abnormalities in the airways may affect their generation. ${ }^{4}$

Firstly, the parenchymal tissue serves as an important conducting medium, along which sounds can propagate towards the chest. ${ }^{17} 18$ Thus the alveolar destruction and enlargement in emphysema potentially compromises lung sound transmission. It has been observed that lung sounds may diminish with increasing lung volume. ${ }^{12} 3132$ Even though we standardised the target volume in our experiments from 0.5 to 2 1 below TLC, the absolute lung volume in the patients might still have been greater than in the normal subjects. Nevertheless, we found no difference in lung sound intensity between the two groups, which indicates that radiographically confirmed parenchymal destruction did not alter lung sound intensity in our patients with emphysema. This is in accordance with the observation that the transmission of artificial sounds introduced at the mouth may be either decreased or increased in emphysema. ${ }^{7}$ Reduced sound transmission therefore does not seem to have a major influence on the auscultatory findings in these patients.

Secondly, any changes in airway geometry may alter the generation of sounds. In emphysema the static shape of the intrapulmonary airways is irregular and tortuous. ${ }^{33}$ This might enhance sound production during inspiration and expiration..$^{14} 34$ On the other hand, the airways may be obstructed in emphysema, as a result of dynamic compression or mural thickening or both, caused by the disease process itself ${ }^{35}$ or by concomitant bronchitis or bronchiolitis. ${ }^{30}$ Apart from potentially causing adventitious lung sounds, ${ }^{36}$ this obstruction results in airflow limitation and reduced ventilation, which has been observed to diminish lung sound intensity. ${ }^{11}{ }^{13} 31$ Indeed, Ploysongsang et al ${ }^{10}$ showed that regional lung sound intensity is correlated with regional ventilation in emphysema, which suggested the hypothesis that an airflow dependent reduction in sound generation could explain the auscultatory findings in this disease. Our present observations favour this hypothesis. Lung sound intensity was dependent on airflow, but appeared to be normal in emphysema when airflow was strictly standardised. Apparently, all other remaining mechanical abnormalities in emphysema do not substantially contribute to the intensity of lung sounds on the chest.

The results of the present study have clinical implications. The reduction in lung sound intensity has been considered as a major clinical criterion for the diagnosis of pulmonary emphysema. $^{2-4}$ This auscultatory finding, however, appears to be highly dependent on airflow, which is likely to be less in patients with emphysema than in normal subjects during the usual physical examination procedures. When airflow is standardised the abnormality disappears, making any inference based on auscultatory examination of lung sound intensity in the clinical diagnosis of emphysema questionable.
We thank Mrs Mieke Timmers for carrying out the lung function tests on the subjects, and Mr Robert Schot and Mr Eli Berkelmans for technical assistance. This study was supported by grant 89.31 of the Netherlands Asthma Foundation.

1 Thurlbeck WM. Pathophysiology of chronic obstructive pulmonary disease. Clin Chest Med 1990;11:389-403.

2 American Thoracic Society. Standards for the diagnosis and care of patients with chronic obstructive pulmonary disease (COPD) and asthma. Am Rev Respir Dis 1987;136: 225-44.

3 Nairn JR, Turner-Warwick $M$. Breath sounds in emphysema. Br J Dis Chest 1968;63:29-37.

4 London R, Murphy RLH. Lung sounds. Am Rev Respir Dis 1984;130:663-73.

5 Bohadana AB, Peslin R, Uffholtz H. Breath sounds in the clinical assessment of airflow obstruction. Thorax 1978; 33:345-51.

6 Kraman SS. Lung sounds for the clinician. Arch Intern Med 1986;146:1411-2.

7 Ploysongsang Y, Paré JAP, Macklem PT. Lung sounds in patients with emphysema. Am Rev Respir Dis 1981;124: 45-9.

8 O'Donnell DM, Kraman SS. Vesicular lung sound amplitude mapping by automated flow-gated phonopneumography. J Appl Physiol 1982;53:603-9.

9 Dosani R, Kraman SS. Lung sounds intensity in normal men. A contour phonopneumographic study. Chest 1983; 83:628-31.

10 Ploysongsang Y, Paré JAP, Macklem PT. Correlation of regional breath sounds with regional ventilation in emphysema. Am Rev Respir Dis 1982;126:526-9.

11 Kraman SS. The relationship between airflow and lung sound amplitude in normal subjects. Chest 1984;86:225-9.

12 Kraman SS. Effects of lung volume and airflow on the frequency spectrum of vesicular lung sounds. Respir Physiol 1986;66:1-9.

13 Shykoff BE, Ploysongsang Y, Chang HK. Airflow and normal lung sounds. Am Rev Respir Dis 1988;137:872-6.

14 Kraman SS, Wang PM. Airflow-generated sound in a hollow canine airway cast. Chest 1990;97:461-6.

15 Thurlbeck WM, Simon G. Radiographic appearance of the chest in emphysema. Am J Roentgenol 1978;130:429-40.

16 Qanjer PhH (ed). Standardized lung function testing. Bull Eur Physiopathol Respir 1983;19(suppl 5):1-95.

17 Kraman SS. Does the vesicular lung sound come only from the lungs? Am Rev Respir Dis 1983;128:622-6.

18 Rice DA. Sound speed in pulmonary parenchyma. J Appl Physiol 1983;54:304-8.

19 Schreiber JR, Anderson WF, Wegmann MJ, Waring WW. Frequency analysis of breath sounds by phonopneumography. Med Instrum 1981;15:331-4.

20 Dalmasso F, Guarene MM, Spagnolo R, Benedetto G, Righini G. A computer system for timing and acoustical analysis of crackles: a study in cryptogenic fibrosing alveolitis. Bull Eur Physiopathol Respir 1984;20:139-44.

21 Kraman SS. The forced expiratory wheeze: its site of origin and possible association with lung compliance. Respiration 1983;44:189-96.

22 Bland JM, Altman DG. Statistical methods for assessing agreement between two methods of clinical measurement. Lancet 1986; i:307-10.

23 Snedecor GW, Cochran WG. Statistical methods. 7th ed. Ames: Iowa State University Press, 1980.

24 Armitage P. Statistical methods in medical research. 6th ed. Oxford: Blackwell, 1983.

25 Pardee NE, Martin CJ, Morgan EH. A test of practical value of breath sound intensity: breath sounds related to measured ventilatory function. Chest 1976;3:341-4.

26 Lohela P, Sutinen S, Pääkkö P, Lathi R, Tienari J. Diagnosis of emphysema on chest radiographs. Fortschr Rötgenstr 1984;141:395-402.

27 Olson DE, Hammersley JR. Mechanisms of lung sound generation. Semin Respir Med 1985;6:171-9.

28 Kraman SS. Vesicular (normal) lung sounds: how are they made, where do they come from, and what do they mean? Semin Respir Med 1985;6:183-91.

29 Hardin JC, Patterson JL. Monitoring the state of the human airways by analysis of respiratory sound. Acta Astronautica 1979;6:1137-51.

30 Niewoehner DE. New messages from morphometric studies of chronic obstructive pulmonary disease. Sem Respir Med 1986;8:140-6.

31 Leblanc P, Macklem PT, Ross WRD. Breath sounds and distribution of pulmonary ventilation. Am Rev Respir Dis 1970;102:10-6.

32 Banaszak EF, Kory RC, Snider GL. Phonopneumography. Am Rev Respir Dis 1973;107:449-55.

33 Linhartova A, Anderson AE, Foraker AG. Further observations on luminal deformity and stenosis of non-respiratory bronchioles in pulmonary emphysema. Thorax 1977;32: 53-9.

34 Kraman SS. Lung sounds: relative sites of origin and comparative amplitudes in normal subjects. Lung 1983; 161:57-64.

35 Linhartova A, Anderson AE. Small airways in severe panlobular emphysema: mural thickening and premature closure. Am Rev Respir Dis 1983;127:42-5.

36 Grotberg JB, Davis SH. Fluid-dynamic flapping of a collapsible channel: sound generation and flow limitation. Journal of Biomechanics 1980;13:219-30. 